\title{
Similarities in the fracture surface features of borosilicate and polymer glasses
}

\author{
TSUNG-YU PAN, RICHARD E. ROBERTSON*, FRANK E. FILISKO \\ Macromolecular Research Center and Department of Materials Science and Engineering, \\ The University of Michigan, Ann Arbor, Michigan 48109-2136, USA
}

Considerable similarity exists between the features on the fracture surfaces of a borosilicate glass and those on the fracture surfaces of polymer thermoset glasses like epoxies and vinyl esters. These features include the steps and welts of the hackle, the arrays of skewed cracks, and the basic longitudinal texture. It was the latter, the basic longitudinal texture, that was the most surprising find on the fracture surfaces of borosilicate glass. On the fracture surfaces of polymer thermoset glasses, the basic longitudinal texture has been interpreted as a remnant from the fracturing process, arising from an instability in the meniscus between air and a polymer layer softened or "liquified" by the stresses of cracking. The meniscus instability results in an array of crack fingers preceding the nominal crack front. By analogy, it is suggested that the borosilicate glass fractures by a similar process, including the softening of the glass ahead of the crack front. The basic longitudinal texture is usually visible only at high magnification and often requires (a necessity for the borosilicate glass fracture surface) the tilting of the normal to the fracture surface toward the detector. The steps, welts and arrays of skewed cracks are simply explained with the crack fingering hypothesis.

\section{Introduction}

The fracture surface characteristics of inorganic glasses have long been studied and the mechanisms of some of the principal features, such as the steps and welts, were long ago correctly described by Preston [1] and others $[2,3]$. The fracture surface features of glassy polymers have received much less attention and most of that rather recently [4-9]. Yet there are many similarities, and some of the findings with polymers, especially thermosets, are able to shed light on the fracturing mechanism in ways that the study of the inorganic glasses has not. The purpose of this report is to describe some new features found on the fracture surfaces of a borosilicate glass that are analogous with those we have recently seen on the surfaces of a number of thermosets, including epoxies and cross-linked polystyrene [9].

\section{Experimental procedure}

\subsection{Materials}

The glass used in this study was Corning Pyrex 7740 borosilicate glass in the form of rods $1 \mathrm{~mm}$ in diameter. This is a low alkali, high silica glass with $13 \mathrm{wt} \% \mathrm{~B}_{2} \mathrm{O}_{3}$; its chemical constituents and physical properties are listed in Table I. To prepare the glass rods for fracture and observation, a parallel array of the rods was embedded in an epoxy matrix to fix their positions. These specimens were also used to study fibre-matrix debonding [10].

For the polymeric glasses, two types of thermosets were used. The first was an epoxy that had been studied previously [9], obtained from a trifunctional aromatic epoxy resin containing a tertiary amine, Ciba-Geigy 0500 , cured with 4-methyl hexahydrophthalic anhydride. It was cured for $30 \mathrm{~min}$ at $120^{\circ} \mathrm{C}$ followed by $30 \mathrm{~min}$ at $150^{\circ} \mathrm{C}$. The completeness of the reaction was indicated by the absence of anhydride as measured by infrared spectroscopy following cure.

The second polymer glass was a vinyl ester. It was obtained from an experimental, low viscosity vinyl ester resin, Dow Derakane XU71835.01L, which consists of the tetrafunctional adduct of acrylic acid and the diglycidyl ether of bisphenol A (DGEBA) dissolved in styrene [11]. This was cured with $2 \mathrm{wt} \%$ Witco BZQ- $40,40 \%$ benzoyl peroxide paste at $80^{\circ} \mathrm{C}$ for $1.5 \mathrm{~h}$.

\subsection{Specimen preparation}

For the borosilicate glass, notched specimens were fractured by three-point bending. The notches were made in the specimens in the centre of one of the long edges by cutting with a saw and sharpening with a razor blade. Fracture was induced with an Instron Universal Testing Machine operating at the slow cross-head speed of $0.051 \mathrm{~mm} \mathrm{~min}^{-1}\left(0.002\right.$ in $\left.\mathrm{min}^{-1}\right)$. After fracture was initiated, fast fracture, of the order of $100 \mathrm{~m} \mathrm{sec}^{-1}$, may have ensued, however. The location of the notch and the bending, about an axis parallel with the glass rods, were arranged so as to induce crack propagation into the crowd of glass rods parallel to their axes. The crack propagated either around or through the glass rods depending on the 
TA BLE I Corning Pyrex 7740 borosilicate glass.

\begin{tabular}{|c|c|c|c|c|}
\hline \multicolumn{5}{|c|}{ Chemical constituents (wt \%) } \\
\hline $\mathrm{SiO}_{2}$ & $\mathrm{Al}_{2} \mathrm{O}_{3}$ & $\mathrm{Na}_{2} \mathrm{O}$ & $\mathrm{K}_{2} \mathrm{O}$ & $\mathrm{B}_{2} \mathrm{O}_{3}$ \\
\hline 80.5 & 2 & 4 & 0.5 & 13 \\
\hline \multicolumn{5}{|c|}{ Physical Properties } \\
\hline \multicolumn{3}{|c|}{ Thermal expansion coefficient } & \multicolumn{2}{|c|}{$3.25 \times 10^{-6} \mathrm{~K}^{-1}$} \\
\hline \multicolumn{3}{|c|}{ Density } & \multicolumn{2}{|c|}{2.23} \\
\hline \multicolumn{3}{|c|}{ Refractive index } & \multicolumn{2}{|c|}{1.474} \\
\hline \multicolumn{3}{|c|}{ Young's modulus } & \multicolumn{2}{|c|}{$63 \mathrm{GPa}$} \\
\hline \multicolumn{3}{|c|}{ Poisson's ratio } & \multicolumn{2}{|c|}{0.20} \\
\hline \multicolumn{3}{|c|}{ Knoop hardness $\mathrm{KHN}_{100}$} & \multicolumn{2}{|c|}{418} \\
\hline
\end{tabular}

surface condition of the glass rods. The fracture surface of the broken glass is the subject for this study.

The fracture of the polymeric glasses also resulted from mode I cleavage. Small blocks of the thermoset glasses were cut from larger pieces, and saw cuts several millimetres deep were inserted into the ends of each. Fracture was induced by driving a knife blade or wedge into the saw cuts.

\subsection{Examination procedure}

The fracture surfaces were examined with a scanning electron microscope (SEM). Prior to this, the fracture surfaces were coated with gold-palladium (Au-Pd). The SEM employed for most of the micrographs was a Hitachi S-520 microscope, operating at an accelerating voltage of $15 \mathrm{kV}$ for the glass and $10 \mathrm{kV}$ for the vinyl ester. The SEM employed for the epoxy was an older JSM-2 microscope operating at an accelerating voltage of $15 \mathrm{kV}$. To enhance the contrast, which was particularly important for the relatively shallow topography of the basic longitudinal texture on the borosilicate glass fracture surfaces, to be discussed below, the specimen normal was tilted away from the incident electron beam toward the detector by an angle in the range of $60^{\circ}$ to $70^{\circ}$.

\section{Results}

\subsection{Steps and welts}

A typical borosilicate glass fracture surface, on which a number of steps are visible, is shown in Fig. 1 and at a slightly higher magnification in Fig. 2. (The features

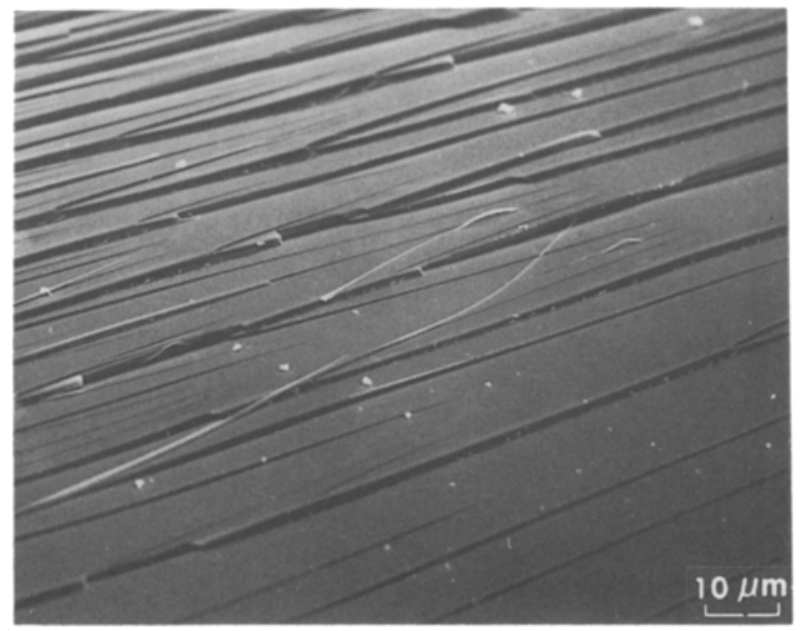

Figure I SEM micrograph of the fracture surface of borosilicate glass. Fracture surface normal tilted $70^{\circ}$ toward detector.

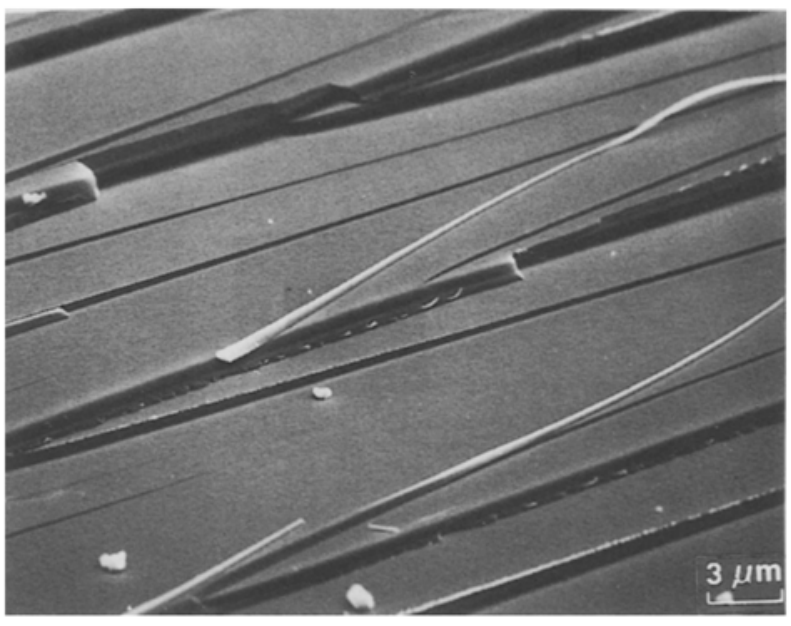

Figure 2 Detall of image in Fig. 1. Larger welts mainly attached to their respective steps in this micrograph, the finer welts largely detached.

that we call here "steps" were termed "hackle-marks" and "escarpments" by Murgatroyd [2] and "cleavage steps" by Gilman [12] and by Swain, Lawn and Burns [3] for example.) Fracture surfaces showing similar features are shown in Fig. 3 for the epoxy and in Figs 4 and 5 for the vinyl ester. The steps result from cracks on different, nearly parallel, planes propagating roughly parallel with the step edges. The different cracks result from bifurcations of the primary crack. Several points of bifurcation, i.e., the points from which new steps seem to be growing, are visible in these micrographs, though the reason for the bifurcation is not directly discernable in any of them. The direction of fracture was from upper right to lower left in Figs 1 and 2 and from right to left in Figs 3 and 5. The steps on each of these surfaces are seen to reach heights of the order of $1 \mu \mathrm{m}$.

Also present on the fracture surface in Figs 1 to 5 are fine fibre-like pieces of the material that are sometimes free, though more often attached to the corners of the steps. They frequently have a white or glowing appearance in SEM micrographs because of electrical charging. They were called "strie" by Preston [1], "cleavage whiskers" by Venables [13], "slivers" by Swain, Lawn and Burns [3], "splinters" by

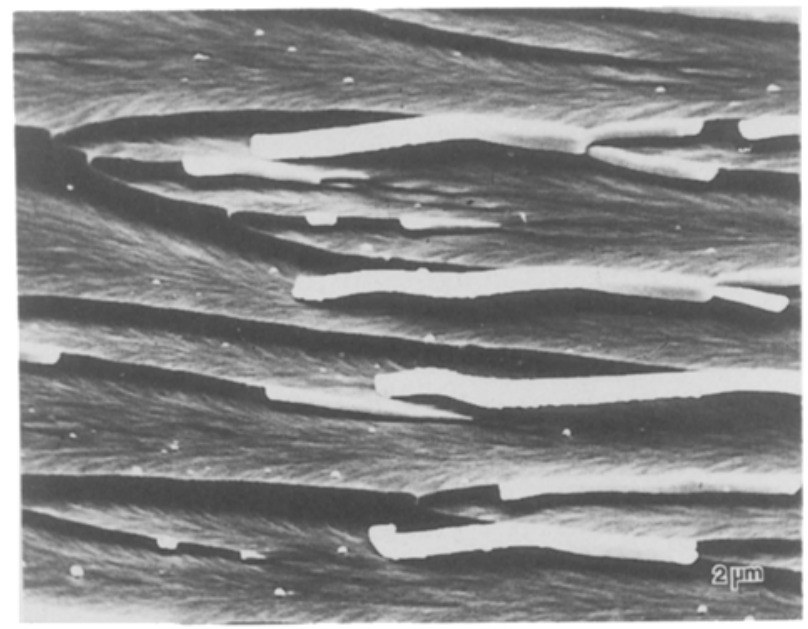

Figure 3 Steps and welts on the fracture surface of a cured epoxy [7]. The welts are largely attached to their respective steps. 


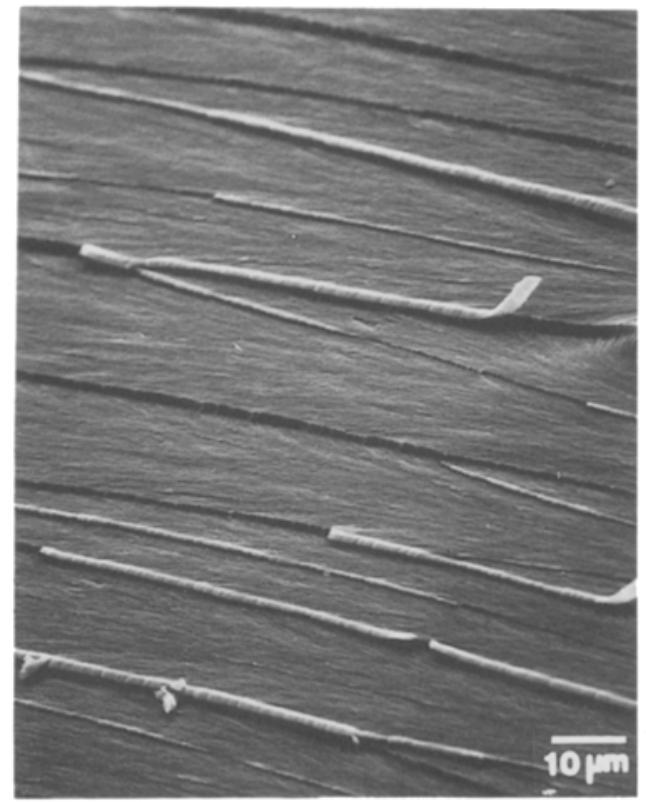

Figure 4 Steps and welts on fracture surface of a cured vinyl ester. Welts are largely detached from their respectve steps.

Murgatroyd [2], "tongue-shaped segments" by Lange [14], and "elongated fragments" by Gilman and Johnston [15]. To use a term more descriptive of their attachment to the corners of steps, we will usually call them "welts", because of their similarity to the trim on the edges of upholstered furniture [16].

Welts are pieces of material cut out by the laterally growing pair of converging cracks that create the steps. A pair of steps is created by the converging pair of cracks, one on each surface. The two steps are slightly displaced, and it is the welt that fills the displacement. There is, however, only one welt shared between the two steps, and on separation of the fracture surfaces, the welt is torn into pieces and distributed between them. On average, then, only about one-half of the steps on each fracture surface will retain, whether free or not, their associated welt.

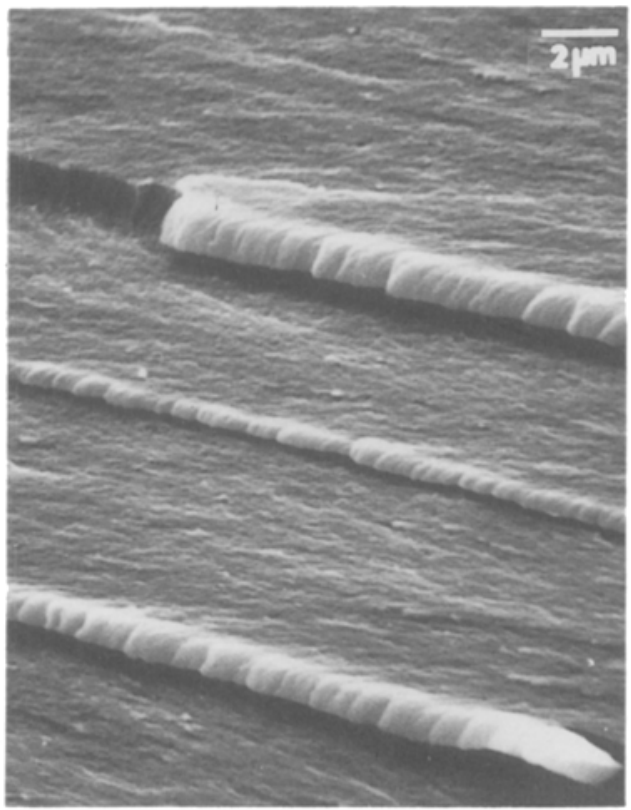

Figure 5 Different view from that in Fig. 4 and at a higher magnification of the steps and welts on fracture surface of vinyl ester.

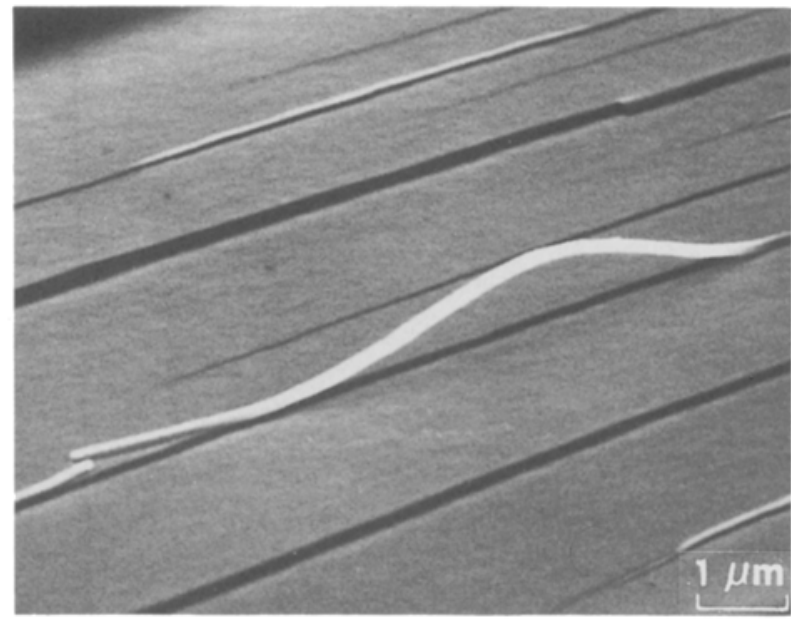

Figure 6 View at higher magnification of a region to the right of centre of Fig. 1, showing a deformed, stretched and broken detached welt. Fracture surface normal tilted $70^{\circ}$ toward detector.

As the welts are divided between the steps on the two opposite surfaces, they are often stretched and otherwise plastically deformed. This has been true of the welts on each of the fracture surfaces in Figs 1 to 5. While perhaps expected for the polymer glasses, its occurrence under tensile and flexural loading with the borosilicate glass was at first a surprise.

The intrinsic plastic deformability at room temperature of the borosilicate is particularly underscored in Figs 6 and 7. A close-up of a detached welt on the borosilicate glass fracture surface is seen in Fig. 6 . This is a magnified view of a region to the right of the centre in Fig. 1. Although all of the welt most prominent here has remained with this surface, its detachment from the opposite surface has resulted in it being plastically deformed into an arch, stretched, and broken at the left end. The curvature of the detached welt is emphasized in Fig. 6, where the surface is viewed from an angle that is about $70^{\circ}$ away from the specimen normal. The elongation of the detached welt is emphasized in Fig. 7, where the surface was viewed approximately normal to the surface, and the same piece of welt appears almost straight. From measurements of the lengths of the welt and the associated step beneath it, the elongation ratio is estimated to be approximated $7 \%$. The occurrence of this large amount

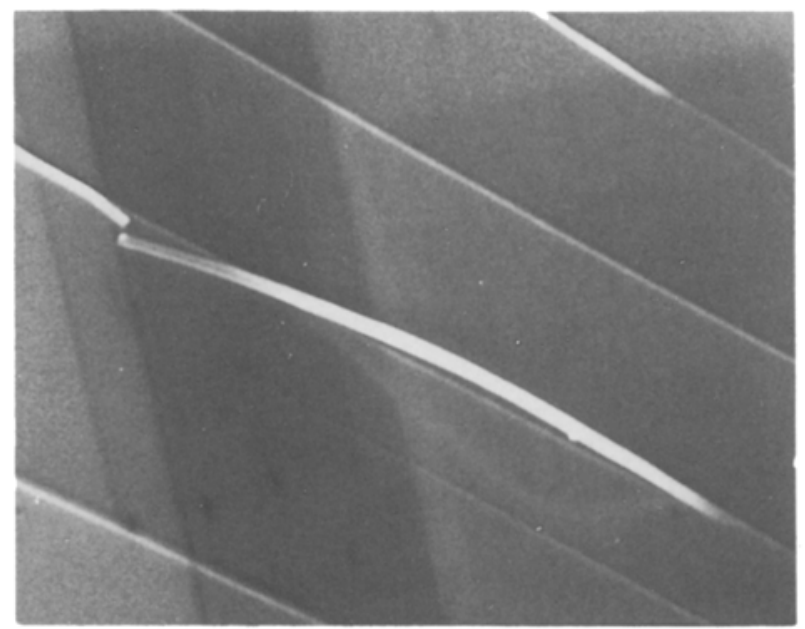

Figure 7 Same piece of welt as in Fig. 6, viewed approximately normal to the surface. 


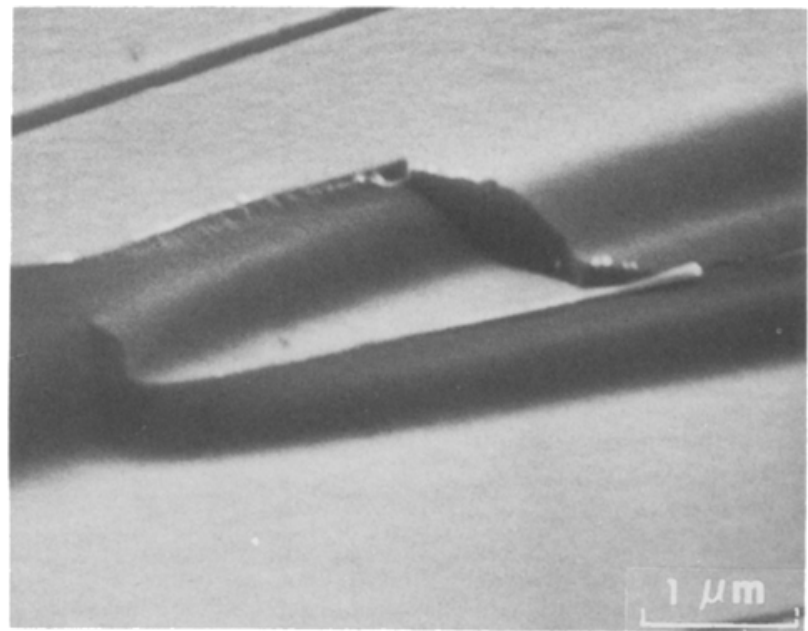

Figure 8 View at higher magnification of region above the centre of Fig. 2 of broken end of an attached welt, showing a stretched parallelogram cross-section. Fracture surface normal tilted $70^{\circ}$ toward detector.

of plastic deformation under tensile and flexural loading suggests that the borosilicate glass here was relatively defect free.

It is difficult to determine accurately the crosssectional shape of most welts. This is due in part to the excessive electrical charging of the welts, which impairs their image, and to the plastic deformation as the welt is torn between the two surfaces. An indication of a typical cross-sectional shape is obtained by viewing the end of a broken step which has not yet been completely separated from the base material. An example for the borosilicate glass is shown in Fig. 8. The crosssectional shape appears to be a rather flat rhombus with a stretching out of the corners at the acute angles of the rhombus. The cross-sectional shape of the epoxy welts is more like a square [9].

\subsection{Basic longitudinal texture}

Readily visible on the terraces between the steps on the fracture surfaces of the polymer glasses in Figs 3 to 5 is a texture called the "basic longitudinal texture" $[9,16]$. It is the smallest-scale texture discernable on the fracture surface even at very high magnifications, and it is parallel to the direction of crack growth. The basic longitudinal texture is not discernible on the borosilicate surface in either Figs 1 or 2, but it is at higher magnification, as in Fig. 9. Fig. 9 is from the central region of Fig. 2. The texture consists of very low ridges and shallow grooves, which in Fig. 9 are elongated from upper right to lower left, along the axis of crack propagation.

Although the basic longitudinal texture is not always readily apparent even on the fracture surfaces of polymer glasses, it is especially difficult to observe the surface of the borosilicate glass. High magnification is required as well as adequate resolution and contrast. For the present borosilicate glass, the basic longitudinal texture was not visible below a magnification of about 10000 times and the specimen normal had to be tilted toward the detector by 60 to $70^{\circ}$.

A question for the interpretation of these micro-

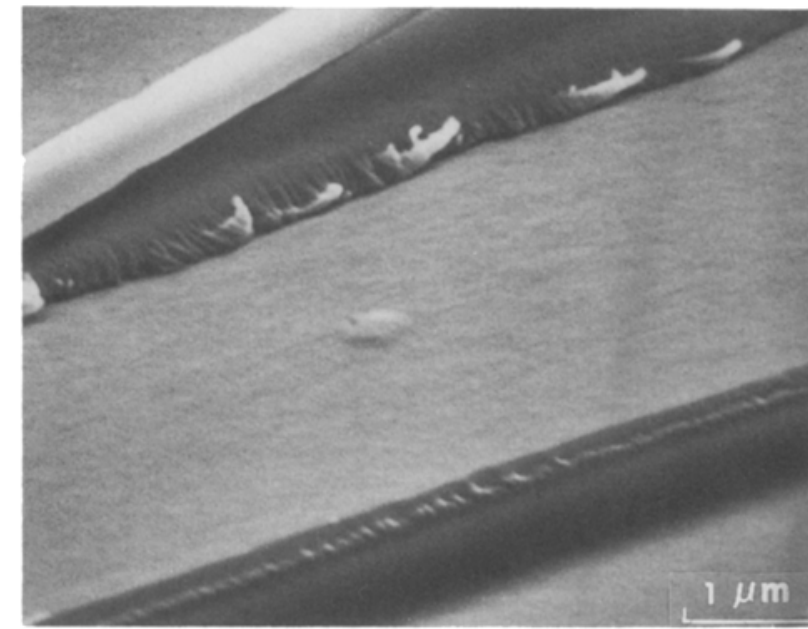

Figure 9 Detail from Fig. 2 (borosilicate glass fracture surface), showing the basic longitudinal texture between steps. Arrays of skewed cracks visible as a fringe on steps and welts. Fracture surface normal tilted toward detector by $70^{\circ}$.

graphs was whether the observed texture seen in Fig. 9, for example, could be an artifact resulting from the high tilting angle. Tilting is known to distort images, tending to produce an apparent light-dark periodicity running parallel with the axis about which the specimen is tilted and to which the human eye is very sensitive. Thus, even completely random textures on the surface tend to adopt a linear appearance as the tilting angle is increased toward $90^{\circ}$.

If the linear texture were simply an image produced by tilting a surface containing only a random topography, the resulting lines would always remain parallel with the tilting axis, irrespective of the specimen orientation. Thus, to examine this question, the specimen was tilted about various axes in the plane of the specimen to bring the specimen surface normal $60^{\circ}$ toward the detector. The texture is shown at six orientations in Figs 10 and 11.

The three micrographs in Fig. 10 show the same region on one of the terraces of the borosilicate glass fracture surface after tilting about three different axes. The axes about which the tilting was performed were all in the plane of the specimen and were for the left, centre, and right micrographs at $-45^{\circ}, 0^{\circ}$, and $45^{\circ}$, respectively, with respect to the crack-growth axis. Although there is a random component to the texture that tends to remain horizontal in each of these micrographs, there is also visible a component that tends to rotate with the specimen, tending to remain parallel with the steps. The left, centre, and right micrographs in Fig. 11 show similar results, except that the longitudinal component of the texture is not discernable in the left-hand picture of Fig. 11. The images in Fig. 11 are from the same regions as in Fig. 10, but from tilting from the normal in the opposite directions, again by $60^{\circ}$. (These positions can be referred to as $135^{\circ}, 180^{\circ}$, and $225^{\circ}$, respectively, with respect to the crack-growth axis.) The images look a little different from those in Fig. 6 because much of the terrace in Fig. 6 was obscured by the adjacent step at this tilting angle. Also, charging at the edge of the step has reduced the quality of the images in these 

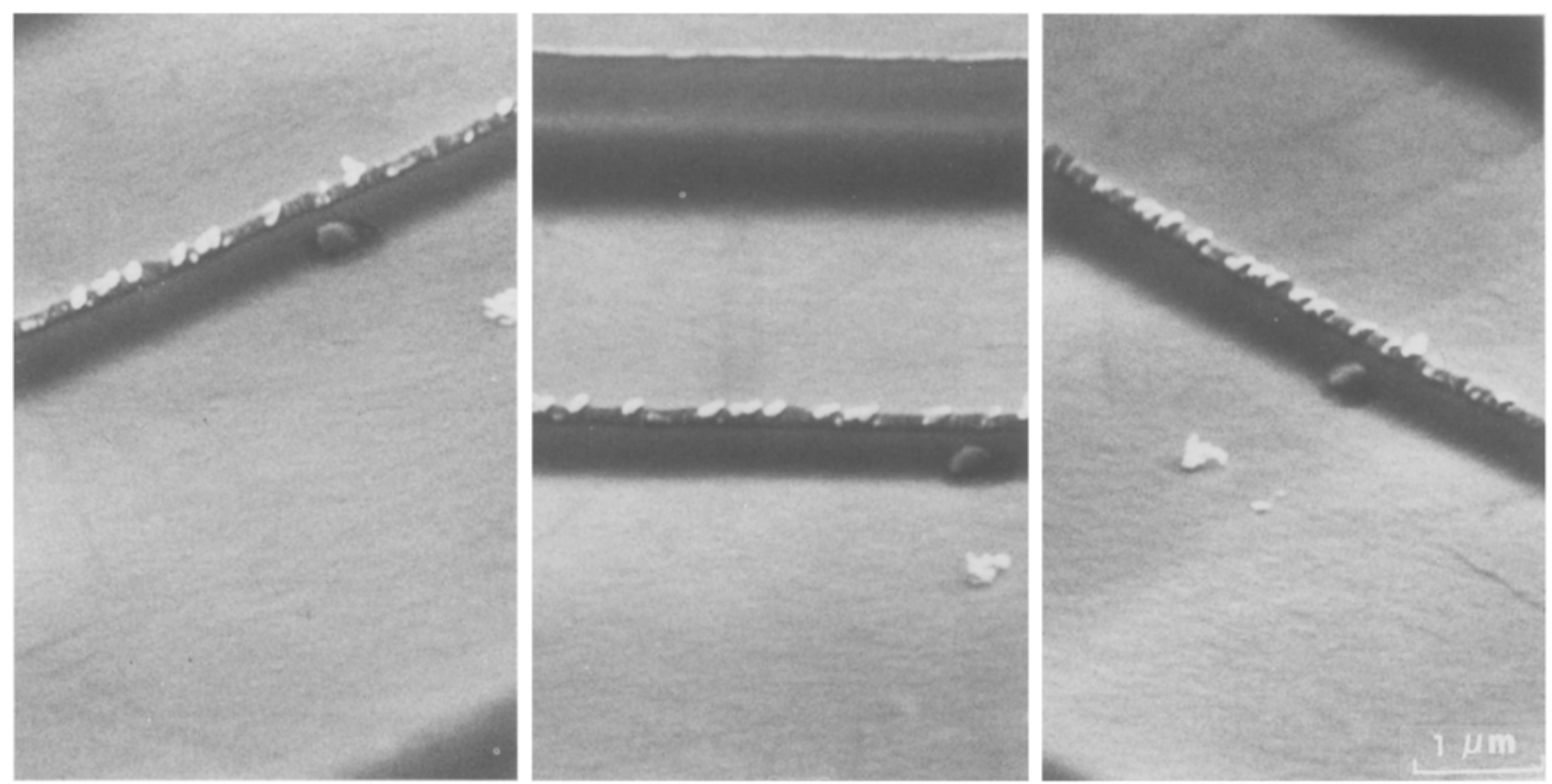

Figure 10 Three orientations of borosilicate glass fracture surface. Each tilted $60^{\circ}$ toward detector about a different axis in specimen plane. Axes were: (centre) parallel with crack-growth axis $\left(0^{\circ}\right)$, (left) rotated $-45^{\circ}$ from crack-growth axis $\left(-45^{\circ}\right)$, and (right) rotated $+45^{\circ}$ from crack-growth axis $\left(+45^{\circ}\right)$.

micrographs. Nonetheless, one can conclude from these experiments that the longitudinal elongation of the texture on the fracture surfaces of the borosilicate glass is real and is not an artifact.

The lateral periodicity of the basic longitudinal texture for the epoxy in Fig. 3 has been estimated to be about $350 \mathrm{~nm} \mathrm{[16].} \mathrm{The} \mathrm{lateral} \mathrm{periodicity} \mathrm{of} \mathrm{the} \mathrm{tex-}$ ture of the vinyl ester in Fig. 5 may be about the same. However, the texture on the surface of the borosilicate glass is so difficult to discern, i.e., the ridges are so low and the grooves are so shallow, that we have been unable to assign a lateral periodicity. It does, however, seem to be distinctly smaller than the $350 \mathrm{~nm}$ estimated for the two polymer glasses.

Another texture has also been seen on the fracture surface of the borosilicate glass. This can be seen in Fig. 12, where the specimen was tilted about $70^{\circ}$ about an axis perpendicular to the direction of crack growth $\left(90^{\circ}\right)$. This texture, the periodicity of which is much longer than that of the basic longitudinal texture, seems to be a result of an undulation of the crack as it has propagated.

\subsection{Arrays of skewed cracks}

A third feature that the fracture surfaces of the polymeric and borosilicate glasses have in common is the remnants of "arrays of skewed cracks". These are sinall, notch-like cracks that are roughly parallel to each other but are tilted or at a skew angle with respect to the axis of the stack. The presence of arrays of
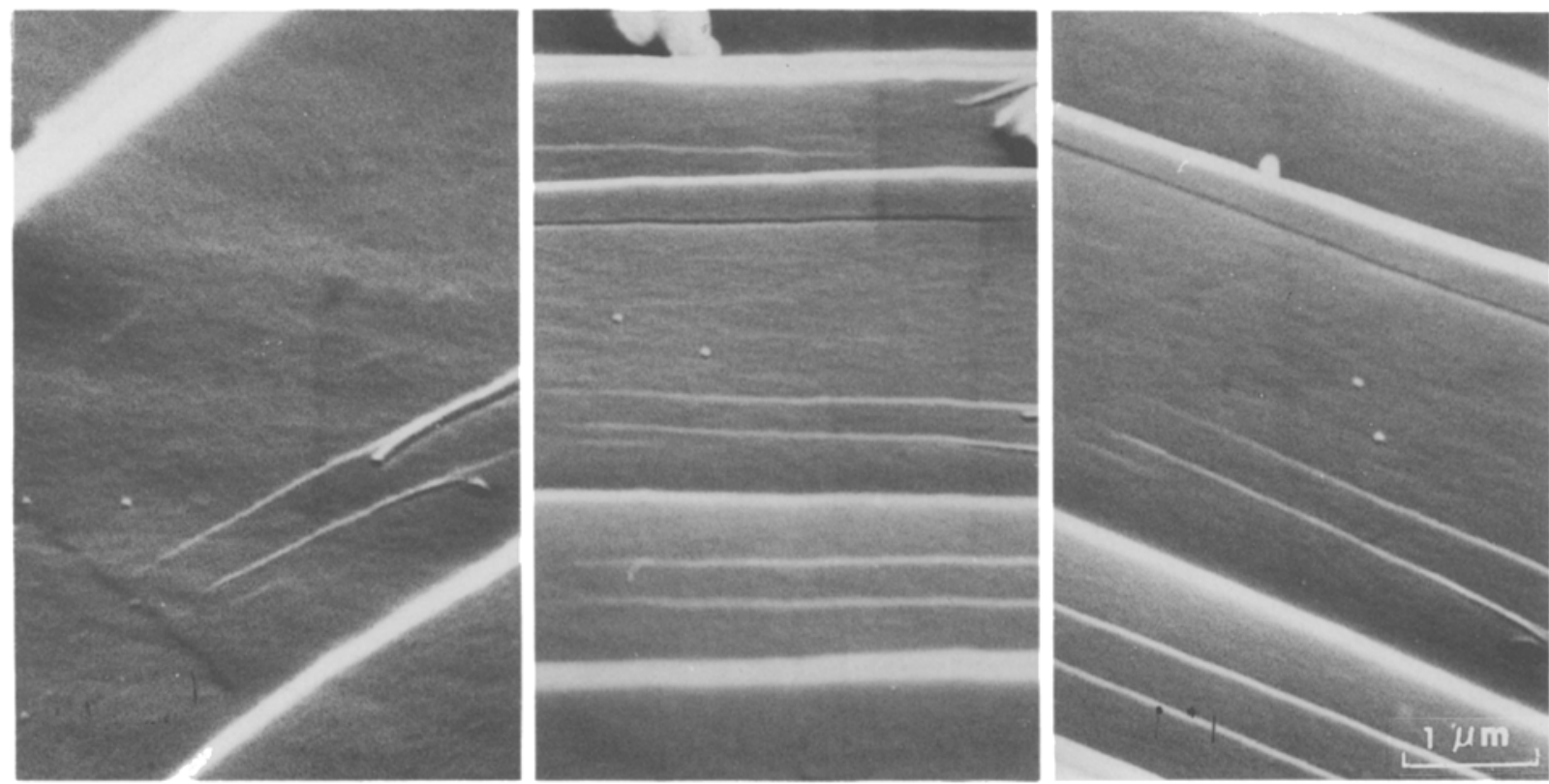

Figure 11 Same region as in Fig. 10; specimen plane also tilted $60^{\circ}$ toward detector. Axes in specimen plane about which specimen had been rotated were: (centre) parallel with the crack-growth axis $\left(180^{\circ}\right)$, but opposite to that in Fig. 10 (centre), (left) rotated $-45^{\circ}$ from the crack-growth axis $\left(135^{\circ}\right)$, and (right) rotated $+45^{\circ}$ from the crack-growth axis $\left(225^{\circ}\right)$. 


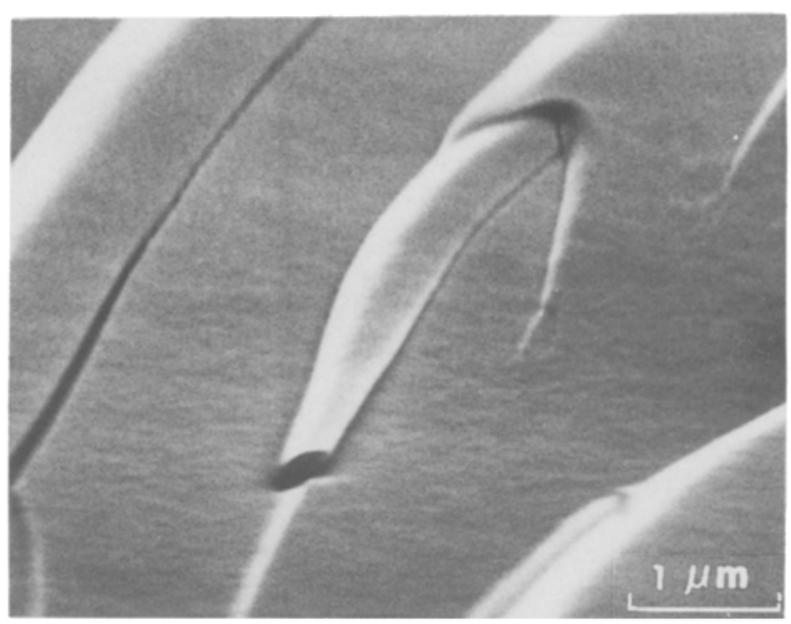

Figure 12 Undulation of crack in propagation direction in borosilicate glass fracture. Fracture surface normal tilted $\sim 70^{\circ}$ toward detector about axis perpendicular to crack-growth axis.

skewed cracks in an extreme, non-tilted form was described earlier for the epoxy, especially where it was associated with fibres in a fibre composite [17]. The cracks were nearly directly over one another and resulted in an assembly of thin petal-like pieces of the epoxy, a texture referred to as a "stacked laminar texture". The arrays of skewed cracks also caused the serration on the surfaces of the welts and on the riser surfaces of the steps seen on the fracture surface of the vinyl ester in Fig. 5. Their presence is discernable on the fracture surfaces of the borosilicate glass. The feather-like texture on the welts in Fig. 9 is the result of an array of skewed crack, as are the grooves on the corner of a step in Fig. 13. A further remnant of an array of skewed cracks is the white, loose material at the edges of the step in Fig. 10.

\section{Discussion}

In some ways, the similarity in the fracture surface characteristics of inorganic and polymer glasses was expected. Both classes of materials undergo typical glassy brittle fracture. Fracture occurs with a snap, and similar noises were emitted. To the naked eye, the resulting surfaces of both appear to be of a similar, conchoidal type of fracture. A similarity in detail is, however, still surprising. Polymer thermoset glasses are generally thought to exhibit a strong inelastic or plastic quality during brittle fracture, but inorganic glasses are not. The results of this work seem to indicate, then, that deductions from common experience are wrong and that the borosilicate glass fracturing at room temperature still exhibits some ductility.

\subsection{Basic longitudinal texture and the crack fingering hypothesis}

The basic longitudinal texture on the surface of a material that is otherwise devoid of structure is strongly suggestive of the so-called meniscus instability in the flow of low viscosity liquids. It is as if the resulting finger-like paths in the liquid had been frozen in-place on the fracture surface. Robertson, Mindroiu, and Cheung [16] agreed with this similarity and suggested that the basic longitudinal texture on the fracture surfaces of the thermoset polymer glasses was indeed

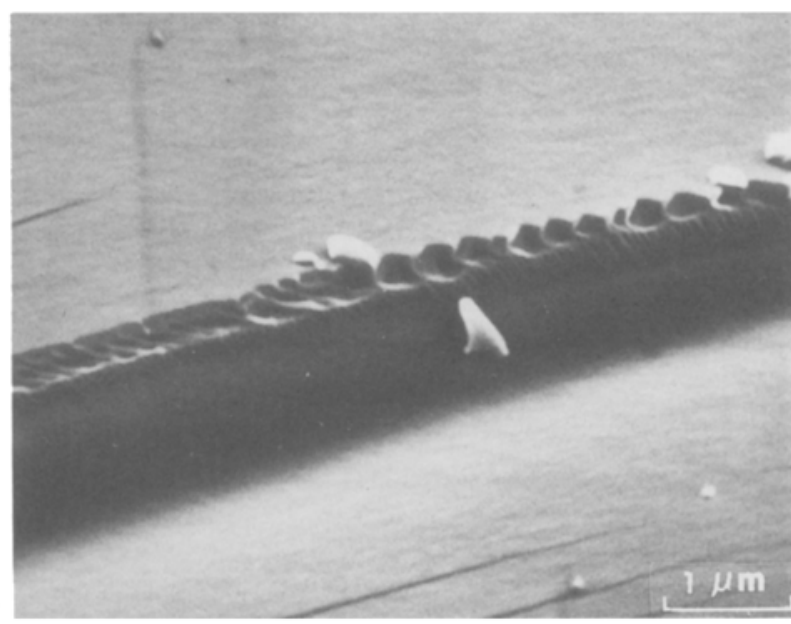

Figure 13 Gouges resulting from "array of skewed cracks" on the borosilicate glass surface. Fracture surface normal tilted $70^{\circ}$ toward detector.

caused by an array of fingers protruding beyond the crack front. More recent results $[18,19]$ advance this theory further and suggest that perhaps polymer glasses undergo a type of liquefaction, similar in nature to yielding, by the large stress field preceding the crack tip. Cracking itself, then, becomes largely the separation of two rigid substrates across a thin layer of liquid.

An instability of the meniscus between two immiscible fluids was first predicted by Taylor [20] and then observed by Lewis [2i] for a pair of fluids of negligible viscosity when accelerated in a direction perpendicular to their interface. The possibility of a meniscus instability during the fracturing of plastically deformable solids was later predicted by Fields and Ashby [22] and by Argon and Salama [23]. This led to the discovery by Donald and Kramer [24] of the growth of crazes in thermoplastics by a "fingering" process related to an instability in the polymer-air or polymervacuum meniscus. The presence of the basic longitudinal texture on the fracture surfaces meant that the concept could be extended to brittle thermoset glasses, as mentioned above, and from evidence for the same texture on the surface of a borosilicate glass, it is suggested that the concept of a liquefaction and resulting meniscus instability also applies to inorganic glasses.

\subsection{Steps and welts}

The formation of the steps and welts has been well described as long ago as 1931 by Preston [1]. Although that work was more concerned with the grosser texture of fracture surfaces, in particular, the location and appearance of the hackle regions, i.e., the fields of steps and welts, it indicated that Preston had also studied the details of the fracture surface topography. Preston noted also the similarity in the fracture surface textures of a large number of materials that are homogeneous, isotropic, and "free from all ductility". These materials include besides "glass" and rocks, materials "that are not essentially brittle" like "pitch, bitumen, resin and even jellies".

There are two aspects to the formation of the steps and welts. The first is the origin and nature of the 
crack-front disturbance; the second is the manner in which the material separates at the riser of the step and the resulting shape of the welt. Both aspects were considered by Preston [1] and more recently by Swain, Lawn, and Burns [3], among others. Swain et al. treated the first aspect rather briefly but the second at length. Although a completely satisfactory analytical description of the manner in which the material separates at the step and the shape given to the welt is perhaps yet to be given, this aspect has received considerable attention. It is the first aspect, the origin and nature of the crack-front disturbance, that has continued to receive insufficient attention.

According to the crack fingering hypothesis, the crack should not be thought of as the taut line it might appear and is usually taken to be. Rather, the crack should be thought of as consisting of a dense array of thin fingers reaching ahead of the nominal crack front. Hence, the break-up of the crack front is implicit, and the assumption of "partial crack fronts" is unnecessary.

An implication of the crack fingering hypothesis is that the fingers are free to respond to the local stress field and the properties of the material through which it passes. One might infer, then, that the individual fingers, only tens to hundreds of nanometres in width, would propagate in very different, diverging directions. While this occurs to some extent, the fingers seem to have a mutual cohesiveness that prevents massive divergence. Yet in efforts to follow spontaneous bifurcations back to their origins, a simple divergence is found. Spontaneous crack bifurcations seem to begin at a point rather than at an interaction of the crack front with a foreign particle, which is also a common mode of crack bifurcation. In working backwards along the slow up-ramp-down-ramp pairs that constitute the spontaneous bifurcation, the initiation sites always have been found to begin simply as a parting between the remnants of adjacent fingers, a parting between pairs of adjacent ridges. Although the cause of bifurcation is usually difficult to discern on the fracture surface, except when it occurs at discrete inclusions, evidence has been advanced for the association of bifurcation with non-uniform stress fields, such as those which arise when sound waves from the noise of fracture are superimposed on the applied stress field [16].

The direction of crack growth during the formation of the welts can be deduced from the basic longitudinal texture, see e.g., the micrographs of the epoxy discussed by Robertson and Mindroiu [9] and of the vinyl ester in Fig. 5. At the top and bottom of this welt the crack has grown largely parallel to the step edge with only a small component of growth in the lateral direction. The texture on the upper, visible surfaces of the welts and the terraces between them indicates only mildly diverging crack growth. The pairs of cracks forming the sides of the welts begin to curl toward each other, however, the cracks seem to grow nearly completely laterally.

Preston also discussed in his 1931 paper the welt shape. He gave an explanation of the formation of welts (or "strie" as he called them) which suggests that he had observed them in greater detail than he men- tioned. He described the stretched parallelogram or rhombic shape that has continued to be described by others and is seen in Fig. 8. His explanation was based on the standard premise that the crack endeavours at all times to stay at right angles to the principal tension in its immediate neighbourhood. He first assumed that the morphology of the hackle and strie on the fracture surface arose from multiple cracks that were the result of a splitting of the crack front by a sudden, unspecified reorientation of the principal stress direction. The steps and welts then arise from the lateral growth of adjacent pairs of crack fronts on different planes. The overlapping cracks curl over, appearing to attract each other, because the direction of the principal tension tilts as the continued crack growth distorts the initial stress field. As the cracks approach, i.e., as the fronts of each approach the fractured surface behind the other, they turn back to their original direction to become parallel again. It is suggested that this arises because the crack fronts are leaving the region where the stress field has been distorted by their presence.

More recent studies, both analytical and experimental, using thermoplastic glasses, have added further details to the shapes of the welts. Sommer [25] fractured a poly(methyl methacrylate) plate with notches on each side and found that a rhombus-like wedge was formed by the two joining cracks. A similar result was described by Melin [26]. In each of these experiments, the pair of cracks, parallel but at slightly different elevations, appear first to repel each other as they begin to overlap and then to attract each other. Before, however, the cracks intersect one another, they turn to become parallel and travel in this fashion for some distance to create a double-ended cantilever. Finally the cracks break through to each other along a rather jagged path resulting from the flexural fracture of the cantilever.

Mills and Walker found similar shapes for the welts produced in unplasticized poly(vinyl chloride) from a stacked array of welts that had been obtained by superimposing anti-plane shear (mode III) stresses on mode I cleavage [27]. The initial repulsion between the cracks as they begin to overlap and subsequent attraction was predicted by Swain, Lawn and Burns [3] from a simple "fracture mechanics" analysis of the stress field. These events were also predicted by Mills and Walker from a two-dimensional elastic analysis using for boundaries arrays of constant displacement dislocation elements that simulated the cracks. This analysis also predicted the tendency later for the cracks to become parallel. In a subsequent computation using linear dislocation elements, which presumably gave more accurate results, however, Mills found that this later parallel growth of the cracks disappeared [28].

The stretched parallelogram or rhombus shape was not found for the welts on the surface of the polymer thermosets. Rather, the welts tended to be squarer which may have resulted from greater deformability of these materials. As a result, the diameter of the welts on the thermoset fracture surfaces tends to be much nearer to the height of the step with which it is associated. 


\subsection{Arrays of skewed cracks}

It is suggested that the arrays of skewed cracks arise from the interaction of the crack fingers with the local stress field during the abrupt reorientation [17]. This is the same explanation used by Preston [1] for the formation of the steps and welts of the hackle, though for this, Preston probably was incorrect. It is nearly the same result as that which occurs when a crack is initiated under mode I cleavage and then continues under mode III cleavage $[25,27,29]$. There is a sudden transition from a relatively smooth to a relatively rough fracture, with the new cracks, twisted slightly with respect to the initial plane, acting as gouges.

The crack fingers are guided largely by the local direction of the maximum resolved tensile stress. If this rotates about an axis that is neither perpendicular to nor parallel with the instantaneous crack direction, the moving crack fingers will both change direction and separate onto different planes. As a result, "stacked lamellar texture", a texture consisting of stacks of overlapping scale- or plate-like lamellae of material, is generated. This is often seen amongst the fibres on the fracture surface of fibre composites [15]. If the stress reorients more abruptly and by a smaller change than that for the stacked lamellar texture, an array of "skewed cracks" will arise and twist slightly with respect to the initial plane acting as gouges [7].

\section{Acknowledgements}

We wish to thank colleagues and students for assistance. In particular, we wish to thank Ms Laura Kirkpatrick for obtaining the micrographs in Figs 4 and 5 and Ms Viorica E. Mindroiu for obtaining the micrograph in Fig. 3.

\section{References}

1. F. W. PRESTON, J. Amer. Ceram. Soc. 14 (1931) 419.

2. J. B. MURGATROYD, J. Soc. Glass Technol. 26 (1942) 155.

3. M. V. SWAIN, B. R. LAWN and S. J. BURNS, J. Mater. Sci. 9 (1974) 175.
4. B. E. Nelson and D. T. TURner, J. Polym. Sci., Polym. Lett. 9 (1971) 677.

5. Idem, J. Polym. Sci., Polym. Phys. Edn 10 (1972) 2461.

6. M. ATSUTA and D. T. TURNER, J. Mater. Sci. Lett. 1 (1982) 167.

7. Idem, Polym. Eng. Sci. 22 (1982) 1199.

8. D. PURSLOW, Composites 17 (1986) 289.

9. R. E. ROBERTSON and V. E. MINDROIU, Polym. Eng. Sci. 27 (1987) 55.

10. T.Y. PAN, R. E. ROBERTSON and F. E. FILISKO, J. Mater. Sci. 23 (1988) 2553.

11. D. A. BABBINGTON, J. BARRON, M. COX and J. ENOS, Proceedings SPI/CI 42nd Annual Conference, February 1987, paper 23-D.

12. J. J. GILMAN, Trans. Metal. Soc. AIME 212 (1958) 310.

13. J. D. VENABLES, J. Appl. Phys. 31 (1960) 1503.

14. F. F. LANGE, Phil. Mag. 16 (1967) 761.

15. J. J. GILMAN and W. G. JOHNSTON, in "Growth and Perfection of Crystals", edited by F. R. N. Nabarro and P. J. Jackson, 1958, p. 84.

16. R. E. ROBERTSON, V. E. MINDROIU and M.-F. CHEUNG, Compos. Sci. Technol. 22 (1985) 197.

17. R. E. ROBERTSON and V. E. MINDROIU, J. Mater. Sci. 20 (1985) 2801.

18. R. E. ROBERTSON, M. G, SPORER, T.-Y. PAN and V. E. MINDROIU, ibid. in press.

19. J. S. COVAVISARUCH, R. E. ROBERTSON and F. W. FILISKO, to be published.

20. G. I. TAYLOR, Proc. R. Soc. A 201 (1950) 192.

21. D. J. LEWIS, ibid. 202 (1950) 81.

22. R. J. FIELDS and M. F. ASHBY, Phil. Mag. 33 (1976) 33.

23. A. S. ARGON and M. SALAMA, Mater. Sci. Eng. 23 (1976) 219.

24. A. M. DONAld and E. J. KRAMer, Phil. Mag. A 43 (1981) 857 .

25. E. SOMMER, Eng. Fract. Mech. 1 (1969) 539.

26. S. T. MELIN, Int. J. Fract. 23 (1983) 37.

27. N. J. MILLS and N. WALKER, Eng. Fract. Mech. 13 (1980) 479.

28. N. J. MILlS, J. Mater, Sci. 16 (1981) 1317

29. W. G. KNAUSS, Int. J. Fract. Mech. $6(1970) 183$.

Received 20 June

and accepted 7 December 1988 